\title{
The Relationship Of Preoperative Anxiety With Perioperative Analgesic Needs In Patients Undergoing Surgery At H. Adam Malik Hospital Medan
}

\author{
Ricksando Siregar*, Akhyar H. Nasution ${ }^{* *}$, Tasrif Hamdi ${ }^{* *}$ \\ *Resident of Anesthesiology and Intensive Therapy USU FK, H. Adam Malik Hospital Medan \\ *** Department of Anesthesiology and Intensive Therapy USU FK, H. Adam Malik Hospital Medan \\ DOI: 10.29322/IJSRP.12.01.2022.p12137 \\ http://dx.doi.org/10.29322/IJSRP.12.01.2022.p12137
}

\begin{abstract}
Background: Anxiety is defined as an unpleasant feeling induced by a fear of a threatening danger; the threat is often unknown, and it often covers a range of emotional and hemodynamic responses. Preoperative anxiety can cause pain in the patient, resulting in an increased need for analgesics

Objectives: Perioperative purpose of this study was to determine the relationship between the degree of anxiety and the need for perioperative analgesic drugs in patients undergoing surgery at $\mathrm{H}$. Adam Malik Hospital, Medan.

Methods: This research design uses analytical descriptive test. The purpose of this study is to see whether there is a connection between preoperative anxiety and the need for perioperative analgesia in patients undergoing surgery at $\mathrm{H}$. Adam Malik Hospital. Assessment of preoperative anxiety using the APAIS score in patients in the handover room in the elective and emergency operating rooms. Then, the use of analgesics before surgery was recorded and assessed on the patient's pain scale using the Visual Analog Score (VAS).
\end{abstract}

Results: This study was followed by 120 subjects who had met the inclusion criteria. This study showed that the distribution of sample characteristics in this study had an average age of 39.15 \pm 13.68 years, $p=0.2$. With the number of male samples as many as $62(51.7 \%)$ samples. In patients experiencing preoperative anxiety where intraoperative analgetic needs in general anesthesia between the two groups were averaged, which was $213.7 \pm 37.5$ $\mathrm{mcg}$ versus $205.7 \pm 16.2 \mathrm{mcg}(\mathrm{p}=0.318)$. While in the postoperative period, the number of analgetic rescue needs in both groups was $295.5 \pm 79.7 \mathrm{mcg}$ versus $230 \pm 113.5 \mathrm{mcg}(\mathrm{p}=0.226)$. With a value of $p>0.05$, there was no statistical difference between the sample with preoperative anxiety and those who were not anxious in the use of intraoperative analgesics and analgetic rescue. This is in contrast to perioperative analgetics where analgetic requirement of $509.2 \pm 107.2 \mathrm{mcg}$ in the sample that experienced anxiety and non-anxious $435 \pm 129.7 \mathrm{mcg}(\mathrm{p}=0.02)$ there was a significant difference between the two variables.

Conclusion: In the General Anesthesia and Regional Anesthesia sample there was a meaningful difference between the use of perioperative analgetics of anxious and non-anxious patients.

Index Terms- APAIS score, Anxiety, Analgesic

\section{INTRODUCTION}

nxiety is defined as an unpleasant feeling induced by a fear A of a threatening danger; the threat is often unknown, and it often covers a range of emotional and hemodynamic responses.(Jawaid M, 2007). In perioperative patient care, preoperative anxiety is an intriguing concept. Patients undergoing elective anesthesia and surgical procedures commonly encounter preoperative anxiety. Even preoperative anxiety is regarded as a normal response in the majority of these patients. Preoperative anxiety can be classified into two categories: anxiety about anesthetic procedures and anxiety about surgical procedures. (Franck LS, 2005).

Age, sex, marital status, education, uncertainty of the day of surgery, patient's ability to comprehend events that occur during surgery, fear of surgery, separation from their family, postoperative pain, fear of the unknown, and feelings of anxiety are all factors that contribute to preoperative anxiety (Thomas V, 1995). The prevalence of preoperative anxiety events varies depending on gender, type of surgery, and the purpose of surgery. Research conducted in Europe, showed the incidence of preoperative anxiety ranged from $27-80 \%$ (Abate et al., 2020). The incidence of preoperative anxiety occurs in $32 \%$ of patients who will undergo surgery under general anesthesia and $50 \%$ of patients who will undergo coronary artery bypass graft (CABG) surgery, where the prevalence is increasing in the Asian population (Sarasekera, 2012). Research conducted at the Haji Adam Malik General Hospital (HAM) on 121 patients planned for elective surgery found preoperative anxiety as measured by the APAIS score, reported to be still very high with a percentage of $48.3 \%$ (Nasution and Tinambunan, 2019).

The Amsterdam Preoperative Anxiety and Information Scale (APAIS) was developed as a practical method for assessing preoperative anxiety. This questionnaire is suitable for predicting postoperative pain (Moerman et al, 1996). The goal of APAIS is to assess preoperative anxiety and the need for patient information in order to identify patients who require additional assistance (Franck LS, 2015). In addition, the stimulation of anxiety can potentiate pain through the psychological system. Pain is influenced by psychological, sensory and emotional conditions as well as cognitive, sociocultural and behavioral factors (Tutuncu \& Gunay, 2011). Pain is a highly complex, subjective and emotional 
sensory experience, with both physicochemical and affective components. The experience of pain is unique to each individual and has wide inter-individual variability. Several studies reported that anxiety was the main psychological predictor of postoperative pain, it was found that postoperative pain intensity was better predicted in people who were not anxious. Preoperative anxiety has long been recognized as a predictor of postoperative pain. However, most of the research so far is still limited to certain surgical procedures (Ocalan et al, 2015).

Anxiety is important because it influences many aspects of the perioperative situation, including preoperative visits, induction, anesthesia maintenance, post-operative demands, and physical recovery. Several studies have shown a correlation between perioperative anxiety and postoperative recovery outcomes. By assessing anxiety in the preoperative period, postoperative pain was determined to be easy to predict (Miguel $\mathrm{RC}$, 2014). It was found that the more anxiety the patient experienced before surgery, the longer the recovery period, and the more severe the pain, because this is the time that makes the patient's anxiety higher. (Lucia A, 2018).

A study conducted by Laufenberg-Feldmann et al in 2018, in 106 patients undergoing lumbar disc surgery, found that $42.5 \%$ of patients had anxiety (GAD-7 score more than 5 or with moderate-severe anxiety symptoms) requiring higher doses of analgesics. higher than non-anxious patients (41.5\% vs $37.7 \%)$ (Laufenberg-Feldmann et al., 2018). In another study, it was also found that there was a relationship between preoperative anxiety with an increased incidence of phantom pain and residual pain after lower extremity amputation surgery and the need for analgesics. Where it was found that $12.7 \%$ of patients experienced phantom pain and 26\% had residual pain (Raichle et al., 2015). Based on the aforementioned, the researchers wished to examine the relation between anxiety and the need for perioperative analgesia in patients undergoing surgery at H. Adam Malik Hospital in Medan.

\section{METHODS}

The analytical descriptive test is used in this research design. The purpose of this study is to see whether there is a connection between preoperative anxiety and the need for perioperative analgesia in patients undergoing surgery at $\mathrm{H}$. Adam Malik Hospital. This study was carried out at H. Adam Malik Hospital Medan and Jejaring Hospital. The study began after receiving ethical clearance and permission from Haji Adam Malik Hospital and the Faculty of Medicine, University of North Sumatra, and continued until the sample count was reached. The study population was all subjects who were going to undergo surgery at Haji Adam Malik General Hospital Medan and at Jejaring Hospital. The research sample is the population that meets the inclusion and exclusion criteria. Inclusion criteria included samples aged 18-65 years, patients undergoing surgery with general anesthesia and regional anesthesia $<3$ hours and patients with ASA physical status I and II. Exclusion criteria in this study were patients with neurological disorders, decreased consciousness and cognitive deficits and the use of antidepressants. While the dropout criteria (Drop Out) is that there is an emergency of the heart and lungs, so the total is 108 and rounded up to 120 samples.
Following approval from the Faculty of Medicine, University of North Sumatra, and General Hospital Haji Adam Malik Medan's Ethics Committee (RSUP HAM). Researchers collected samples from all patients who underwent surgery under general anesthesia or regional anesthesia and were registered at the H. Adam Malik Hospital's Central Surgical Installation and Emergency Surgery Installation. Identification of research participants based on the acceptance and rejection criteria that have been established. The researcher conducted the identification of the research participants during the preanesthesia visit. The researcher obtained informed consent by describing the research objectives, research procedures, possible benefits, and hazard in this study. If the patient expresses an interest in participating in the study, this will be documented by signing the research consent form. Patients who refused to participate in the study would continue to receive standard perioperative care but would be excluded from the study. After signing the informed consent form, the patient was assessed for preoperative anxiety using the APAIS score in the handover room in both the elective and emergency operating rooms. The use of analgesics prior to surgery was then documented and analyzed using the Visual Analog Score on the patient's pain scale (VAS). Peripheral venous access and monitoring are installed while the patient is in the operating room. There are 2 kinds of anesthesia used: general anesthesia and regional anesthesia (RA-SAB and Epidural). Patients under general anesthesia were given premedication Midazolam $0.05 \mathrm{mg} / \mathrm{KgBW} /$ intravenous and fentanyl $2 \mathrm{mcg} / \mathrm{KgBW} /$ intravenously. Then the induction was carried out using propofol $2 \mathrm{mg} / \mathrm{KgBW} /$ intravenously followed by the administration of the relaxant rocuronium 1 $\mathrm{mg} / \mathrm{KgBW} /$ intravenously. After drug onset was achieved, intubation was performed using a size 7.5 (male) and a size 7 (female) ETT. Maintenance anesthesia using isoflurane 1,2 MAC. At the time of the surgical incision, fentanyl was given 1 $\mathrm{mcg} / \mathrm{KgBW} /$ intravenous maintenance. Meanwhile, patients with the RA-SAB anesthetic technique used the local anesthetic agent bupivacaine $0.5 \%$ heavy dose of $10-15 \mathrm{mg}$, while patients with the RA-Epidural technique used $0.75 \%$ ropivacaine.

Furthermore, the hemodynamic changes (blood pressure, pulse rate, oxygen saturation, heart rhythm, urine output) of the patient during surgery were recorded. As well as recording the addition of analgesic drugs during surgery. This assessment was carried out by volunteers who were involved since the beginning of the study (PPDS Anesthesia who had passed the general anesthesia stage). Postoperatively, the patient was given ketorolac $30 \mathrm{mg} /$ intravenous in the recovery room, T0 was assessed at 2 hours after surgery. Then the patient's pain scale was assessed using VAS at 12 hours postoperatively (T1) then at 24, 48, 72 postoperative hours, and calculated the number of analgesic needs per day. If the VAS value is 4 , the patient will receive rescue analgesics in the form of fentanyl $0.5 \mathrm{mcg} / \mathrm{kgBW} / \mathrm{hour}$ intravenously. The amount of analgesic use was accumulated up to 72 hours postoperatively. As well as the QoR-15 assessment. The results of the observation data on the sample were collected and processed statistically using SPSS Software.

\section{RESULTS}

This research was carried out in September - October 2021 at the Haji Adam Malik General Hospital Medan. This study is a descriptive analytic study, with the aim of knowing the 
relationship between the degree of preoperative anxiety and the need for perioperative analgesia in patients undergoing surgery at Haji Adam Malik General Hospital Medan. The research subjects were patients aged 18-65 years with physical status PS ASA 1 and 2 , who underwent surgery under general anesthesia and regional anesthesia with a duration of surgery less than 3 hours. A preoperative anxiety scale and perioperative analgesic need were assessed for up to 72 hours postoperatively. This study included 120 patients who met the inclusion criteria. Table 1 displays the characteristics of test subjects in the form of frequency, mean with standard deviation, median with minimum and maximum values, and normality test.

Table 1. Characteristics of Research Subjects

\begin{tabular}{lll}
\hline Characteristics & Subject & $\mathrm{p}^{\mathrm{a}}$ Value \\
\hline Age (year, mean \pm SD) & $39,15 \square 13,68$ & 0,20 \\
\hline Gender (n, \%) & $62(51,7)$ & 0,07 \\
Male & $58(48,3)$ & \\
Female & & \\
\hline Ethnic (n,\%) & & \\
\hline Batak & $56(46,7)$ & 0,001 \\
Minang & $7(5,8)$ & \\
Jawa & $47(39,2)$ & \\
Melayu & $9(7,5)$ & \\
Tionghoa & $1(0,8)$ & \\
\hline Religion (n,\%) & & \\
\hline Islam & $77(64,2)$ & \\
Kristen & $42(35)$ & \\
Buddha & $1(0,8)$ & \\
\hline Type of Anaesthesia (n, \%) & $55(45,8)$ & \\
\hline GA & & \\
Regional & & \\
\hline & & \\
\hline
\end{tabular}

Based on Table 4.1, it shows that the distribution of sample characteristics in this study has a mean age of $39.15+13.68$ years, $\mathrm{p}=0.2$. With the number of male samples as many as $62(51.7 \%)$ samples. Based on the type of anesthesia, the samples with general anesthesia were 55 samples and 65 samples with regional anesthesia. With $\mathrm{p}>0.05$, then based on age and gender the sample is said to be normally distributed or homogeneous.

Descriptions of preoperative anxiety in the sample undergoing surgery under general anesthesia and regional anesthesia are shown in Table 2.

Table 2. Incidence of general anesthesia preoperative anxiety

\begin{tabular}{llll}
\hline Anxiety Scale & \multicolumn{2}{c}{ P value } \\
\cline { 2 - 3 } & Anxiety & Not Anxiety & 0,001 \\
\hline GA $(\mathrm{n}=55)$ & $14,38 \pm 3,77$ & $7,27 \pm 1,71$ & \\
\hline Total & 29 & 26 & \\
\hline
\end{tabular}

Table 2 shows that in the sample that underwent surgery with general anesthesia there were 29 samples who experienced preoperative anxiety, with an APAIS score of $14.38 \pm 3$, there was a statistically significant difference in preoperative anxiety between samples undergoing surgery and general anesthesia. 
Table 3. Incidence of regional anesthesia preoperative anxiety

\begin{tabular}{llll}
\hline Anxiety Scale & \multicolumn{2}{c}{ P value } \\
\cline { 2 - 3 } & Anxiety & Not Anxiety & 0,001 \\
\hline Regional $(\mathrm{n}=65)$ & $14,46 \pm 2,07$ & $7,23 \pm 1,79$ & \\
\hline Total & 35 & 30 & \\
\hline
\end{tabular}

Table 3 shows that in the sample that underwent surgery with general anesthesia there were 65 samples who experienced preoperative anxiety, with an APAIS score of $14.46 \pm 2.07$, there was a statistically significant difference in preoperative anxiety between samples undergoing surgery with regional anesthesia.
Description of the sample pain scale at the time of preoperative, and postoperative based on the Visual Analog Scale (VAS) in the sample with general anesthesia and regional anesthesia is shown in Table 3.

Table 4. Preoperative and postoperative pain scale samples with general anesthesia

\begin{tabular}{llll}
\hline Time & Pain Scale (VAS) & \multicolumn{2}{c}{ P value $^{\mathrm{c}}$} \\
\cline { 2 - 3 } & Anxiety (n=29) & $\begin{array}{l}\text { Not Anxiaety } \\
\text { (n=26) }\end{array}$ & \\
\hline Pre-Operative & $3,39 \square 1,89$ & $3,19 \square 0,78$ & 0,014 \\
\hline Post-operative & $3,93 \square 1,13$ & $2,27 \square 1,04$ & 0,001 \\
24 hours (T1) & $1 \square 0,5$ & $1,73 \square 0,77$ & 0,001 \\
48 hours (T2) & $1,79 \square 0,81$ & $2,19 \square 0,98$ & 0,106 \\
72 hours (T3) &
\end{tabular}

Table 4 shows the mean VAS values of patients with general anesthesia at preoperative and postoperative times. In the preoperative assessment, it was found that the sample with preoperative anxiety had a mean VAS of $3.39+1.89$ and not anxious, namely $3.19+0.78, \mathrm{p}$ value $=0.014$. While the postoperative VAS assessment at 24 hours, 48 hours, and 72 hours, respectively, the samples with preoperative anxiety were
$3.93+1.13,1+0.5$, and $1.79+0.81$. Meanwhile, in the nonanxious sample, the mean postoperative VAS was $2.27+1.04$, $1.73+0.77,2.19+0.98$. With $\mathrm{p}$ value $=0.001$ then there is a significant difference between the VAS value of the sample with anxiety and not anxiety at 24 and 48 hours.

Table 5. Preoperative and postoperative pain scale samples with regional anesthesia

\begin{tabular}{llll}
\hline Time & Pain Scale (VAS) & \multicolumn{2}{c}{ P value $^{\mathrm{c}}$} \\
\cline { 2 - 3 } & Anxiety (n=35) & Not Anxiety (n=30) & \\
\hline Pre-Operative & $3,28 \square 1,39$ & $2,69 \square 0,78$ & 0,022 \\
\hline Post-operative & & & \\
24 hours (T1) & $3,86 \square 1,16$ & $2 \square 0,74$ & 0,001 \\
48 hours (T2) & $1,14 \square 0,77$ & $1,6 \square 0,93$ & 0,043 \\
72 hours (T3) & $1,66 \square 0,59$ & $2,2 \square 0,96$ & 0,007 \\
\hline
\end{tabular}

Table 4.5 shows the mean VAS values of patients with general anesthesia at preoperative and postoperative times. In the preoperative assessment, it was found that the sample with preoperative anxiety had a mean VAS of $3.28+1.39$ and not anxious, namely $2.69+0.78$. The samples with preoperative anxiety had postoperative VAS scores of $3.86+1.16,1.14+0.77$, and $1.66+0.59$ at 24 hours, 48 hours, and 72 hours, respectively. Meanwhile, the mean postoperative VAS in the non-anxious group was $2+0.74,1.6+0.93$, and $2.2+0.96$. There is a substantial difference in the VAS value of the sample with anxiety and the sample without anxiety at 24,48 , and 72 hours, with p value $<0.005$.

\section{DISCUSSIONS}

In this study, we assessed the incidence of preoperative anxiety in patients undergoing surgical procedures and their association with perioperative analgesic use and assessed the patient's postoperative pain scale. As is well known, Anxiety in the preoperative period is not only an unpleasant emotional state, but can cause significant psycho-physiological disorders. A study by William et al, showed that high preoperative anxiety scores led to an increase in postoperative analgesic requirements and length of stay (Williams, 1968). 
In this study, the average age of the sample was $39.15+13.68$ years and the number of samples was comparable based on gender ( $51.7 \%$ male vs $48.3 \%$ female). In general, age and gender are predictors for pain and postoperative analgesic use, whereas age blunts peripheral nociceptive function thereby reducing pain intensity. However, there are still not enough studies assessing the correlation between age and the incidence of postoperative pain (Perry et al, 1994; Rudin et al, 2008). In another systematic study, it was stated that preoperative pain, anxiety, age, and type of surgery were predictive factors of postoperative pain intensity. In fact, age, psychological distress, and type of surgery are predictive factors for postoperative analgesic use (Ip et al, 2009).

In addition, from this study, the incidence of preoperative anxiety was $53.3 \%$. This is not much different from a metaanalysis study which states that the prevalence of preoperative anxiety in patients who will undergo surgery is $48 \%(95 \%$ confidence interval) from 28 studies. The high incidence of preoperative anxiety may be due to several things, including the lack of understanding of anesthesia and surgery, and the limited options for postoperative pain management because the majority of the population comes from developing countries (Abate et al, 2020).

In one study, samples with higher anxiety scores tended to experience postoperative pain, with VAS at 24 and 48 hours being strongly correlated with pain sensitivity (Kil et al., 2011). This was also found in our study, where the use of rescue analgesics was more in the sample who experienced preoperative anxiety. And the use of rescue analgesics only in the period of 24 and 48 hours. In this study, it was found that the use of rescue drugs increased in samples experiencing anxiety. This is in accordance with research conducted by Ahmet Ahtan 2019 where the use of rescue was found in groups experiencing anxiety and a similar study conducted by Ismail 2019 where the use of fentanyl in patients who experienced anxiety increased compared to those who did not experience anxiety. A study conducted by Laufenberg-Feldmann et al in 2018, in 106 patients undergoing lumbar disc surgery, found that $42.5 \%$ of patients had anxiety (GAD-7 score more than 5 or with moderate-severe anxiety symptoms) requiring higher doses of analgesics. higher than non-anxious patients $(41.5 \%$ vs $37.7 \%$ ) (Laufenberg-Feldmann et al., 2018).

In this study also assessed the quality of postoperative recovery as assessed by QoR-15. However, there was no difference between the sample who experienced preoperative anxiety and those who were not anxious $(95.9+15.3$ vs $99.8+10.9$ [p = 0.1]). QoR-15 itself, can be used to identify patients who do not recover as expected and the intervention that needs to be carried out. QoR-15 can also show differences in recovery quality between sexes (Chapazis et al, 2016). However, no source has been discovered that evaluates the relationship between preoperative anxiety and patient recovery quality. The limitations of this study are the number of samples undergoing general and regional differences so that the desired results are not optimal, and there is also no control group so that it cannot describe the use of rescue drugs between samples.

\section{CONCLUSION}

The median blood urea nitrogen level on the first day of ICU admission was $14 \mathrm{mg} / \mathrm{dL}(26-308)$, and the median on the third day of admittance was $154 \mathrm{mg} / \mathrm{dL}(45-274)$, with data that had not been normally distributed. The median serum creatinine on the first day of ICU admission was $3.35 \mathrm{mg} / \mathrm{dL}(1.4-9.47)$, and the median on the third day was $3.89 \mathrm{mg} / \mathrm{dL}(1.02-12.70)$, with records not available. With data normally distributed, the average urine output on the first day of ICU admission was $1077.88 \mathrm{ml} / 24$ hours (SD 298.07). On the third day of ICU admission, the mean urine output was $974.4 \mathrm{~m}: / 24$ hours $(600-$ $1944)$, with data not normally distributed. There was no significant effect of low-dose furosemide on AKI and kidney function improvement in septic patients with AKI at H. Adam Malik General Hospital. There was no significant difference in the median between low-dose furosemide administration and blood urea nitrogen $(p=0.758)$ or serum creatinine levels $(p=0.993)$. There is no statistically significant correlation between low-dose furosemide administration and urine output volume $(\mathrm{p}=0,634)$.

\section{REFERENCES}

[1] Abate SM., Chekol YA., Basu B., 2020. Global prevalence and determinants of preoperatif anxiety among surgical patients : A Systematic review and meta- analysis. Int Journal of Surgery Open $25: 6-16$

[2] Berth, H., Petrowski, K., Balck, F., 2007. The Amsterdam Preoperatif Anxiety and Information Scale (APAIS) - the first trial of a German version. Undefined

[3] Boker, A., Brownell, L., Donen, N., 2002. The Amsterdam preoperatif anxiety and information scale provides a simple and reliable measure of preoperatif anxiety. Can. J. Anesth. Can. d'anesthésie 49, 792-798.

[4] Celik F., Edipoglu IS., 2018. Evaluation of preoperatif anxiety and fear of anesthesia using APAIS score. Aur J Med Res. 23:41

[5] Chazapis M., Walker EM., Rooms MA., et al., 2016. Measuring quality of recovery-15 after day case surgery. British J of Anaesth. 116 (2):241-8

[6] Ferrini, F. 2013. Microglia Control Neuronal Network Excitability via BDNF Signalling. Hindawi.

[7] Franck, L.S., Spencer, C., 2005. Informing parents about anaesthesia for children's surgery: a critical literature review. Patient Educ. Couns. 59, 117125 .

[8] Ip HY., Abrishami A., Peng PW., et al., 2009. Predictors of postoperatif pain and analgesic consumption: a qualitative systematic review. Anesthesiology. 111:657-677

[9] Jawaid, M., Mushtaq, A., Mukhtar, S., Khan, Z., 2007. Preoperatif anxiety before elective surgery. Neurosciences (Riyadh). 12, 145-148.

[10] Julian LJ., 2011. Measures of anxiety. Arthritis care res (11); 63 (011)

[11] Kil, H.K., Kim, W.O., Chung, W.Y., Kim, G.H., Seo, H., Hong, J.-Y., 2012.

[12] Preoperatif anxiety and pain sensitivity are independent predictors of propofol and sevoflurane requirements in general anaesthesia. Br. J. Anaesth. $108,119-125$.

[13] Konnecke, H., \& Bechmann, I. 2013. The Role of Microglia and Matrix Metalloproteinases Involvement in Neuroinflammation and Gliomas. Hindawi Publishing Corporation Clinical and Developmental Immunology.

[14] Laufenberg-feldmann R., Kappis B., Camara RJ., Ferner M., 2018. Anxiety and its 67 predictive value for pain and regular analgesic intake after lumbar disc surgery- a prospective observational longitudinal study. BMC psychiatry. 18 (1):82

[15] Maranets, I., Kain, Z.N., 1999. Preoperatif anxiety and intraoperative anesthetic requirements. Anesth. Analg. 89, 1346-51.

[16] Moerman, N., van Dam, F.S., Muller, M.J., Oosting, H., 1996. The Amsterdam Preoperatif Anxiety and Information Scale (APAIS). Anesth. Analg. 82, 445- 51.

[17] Meyer, RA. Ringkamp, M. Campbell, JN., 2006. Peripheral neural mechanism of nociception. In : McMahon SB, Koltzenburg M, editors. Textbook of Pain, 5th ed. China : Churchill Livingstone. pp. 8-19.

[18] Morgan GE, Mikhail MS, Murray MJ. Perioperative pain managament \&enhanched outcomes. In: Clinical anesthesiology, 5th ed. Lange Medical Books/McGraw-Hill, 2015: 1087-105. 
[19] Nackley GA., Tan KS., Fecho K., et al., 2007. Cathecol-O-methyltransferase inhibitor increases pain sensitivity through activation of both beta2- and beta3- adrenergic receptors. Pain. 128 (3):199-208

[20] Perry F., Parker K., White P., 1994. Role of psychological factors in postoperatif pain control and recovery with patient-controlled analgesia. Clin J Pain. 10:57- 63

[21] Raichle KA., Osborne T., Jensen M., et al., 2015. Preoperatif state anxiety, acute postoperatif pain and analgesic use in persons undergoing lower limb amputation. Clin J Pain. 31 (8):699-706

[22] Rawal, N. Fischer, HBJ. Ivani, G., 2008. Post operative pain management good clinical practice. Europian Society of Regional Anestesi. Sweden. pp. $1-2$.

[23] Rudin A., Wolner-Hanssen P., hellbom M,. 2008. Prediction of postoperatif pain after a laparoscopic tubal ligation procedure. Acta anaesth Scand 52:938-45

[24] Samarasekera, D.N., 2012. Preoperatif anxiety in surgical patients experience of a single unit. Acta Anaesthesiol. Taiwanica 50, 3-6.

[25] Sommer M, de Rijke JM, van Kleef M, Kessels AG, Peters ML, GeurtsJW et al. The prevalence of postoperatif pain in a sample of 1490 surgical inpatient. Eur J Anaesthespsiol, 2008; 25: 267-74 68

[26] Tinambunan PM., Nasution AH., Tanjung QF., 2019. Pengaruh kunjungan preoperatif pada pasien operasi elektif terhadap kejadian anxietas di Rumah Sakit Umum Pusat Haji Adam Malik Medan. Repositori Institusi USU.

[27] Thomas V., Heath M., Rose D., Flory P., 1995. Psychological characteristics and the effectiveness of patient-controlled analgesia. Br J Anaesth 74: 271276

[28] Tsigos, C., Kyrou, I., Kassi, E., Chrousos, G.P., 2000. Stress, Endocrine Physiology and Pathophysiology, Endotext. MDText.com, Inc.

[29] Valenzuela Millán, J., Barrera Serrano, J.R., Ornelas Aguirre, J.M., 2010. Anxiety in preoperatif anesthetic procedures. Cir. Cir. 78, 147-151.
[30] Wetsch, W.A., Pircher, I., Lederer, W., Kinzl, J.F., Traweger, C., HeinzErian, P., Benzer, A., 2009. Preoperatif stress and anxiety in day-care patients and inpatients undergoing fast-track surgery. Br. J. Anaesth. 103, 199-205

[31] Williams, J., Jones JR., 1968. Psychophysiological responses to anesthesia and operation. JAMA, 203:415-7

[32] Woolf CJ. 2004. Pain. Moving from symptom control toward mechanismspesific pharmacologic management: Annals of Internal Medicine, 140: 44151

\section{AUTHORS}

First Author - Ricksando Siregar, Resident of Anaesthesiology and Intensive Therapy, Faculty of Medicine, Universitas Sumatera Utara, Medan, Indonesia, ricksandosiregar@gmail.com

Second Author - Akhyar H. Nasution, Department of Anaesthesiology and Intensive Therapy, Faculty of Medicine, Universitas Sumatera Utara, Medan, Indonesia, akhyarhamonangan@gmail.com

Third Author - Tasrif Hamdi, Department of Anaesthesiology and Intensive Therapy, Faculty of Medicine, Universitas Sumatera Utara,Medan, Indonesia, tasrifhamdi@yahoo.com

\section{Correspondence Author -Ricksando Siregar, ricksandosiregar@gmail.com, 081265224363}

